\title{
Impact of Sleep Patterns on Glycaemic Levels in Healthy Young Adults
}

\author{
Nanditha Venkatesann ${ }^{1}$, Rachita Nanda², Suprava Patel ${ }^{3}$, Eli Mohapatra ${ }^{4}$ \\ 1,2,3,4 Department of Biochemistry, AIIMS, Raipur, Tatibandh, Raipur, Chhattisgarh, India.
}

\section{ABSTRACT}

\section{BACKGROUND}

The incidence of sleep disorders is high in diabetes mellitus making the American Association of Diabetes recommend evaluation of sleep quality and duration a part of medical evaluation in these patients. However, with mounting evidence that sleep disturbances could play a major factor in the above disorder, this study aims to understand the impact of sleep patterns on glycaemic level in healthy young adults.

\section{METHODS}

A cross-sectional survey of medical students of AIIMS, Raipur was conducted where demographic and anthropometric details were collected. The sleep duration and quality was noted using the Pittsburgh Sleep Quality Index along with a questionnaire for other information. Biochemical parameters like glucose, insulin and lipid profile were measured for all participants. The patients were grouped into adequate ( $>7$ hours) and inadequate ( $<7$ hours) sleep duration sleepers. Comparison and correlation was performed with independent t test, Chi-Square test and correlation coefficient. Logistic regression was used for odds ratio calculation of risk category.

\section{RESULTS}

Inadequate sleepers had a high BMI $(p=0.02)$ and altered indicators of insulin resistance $(p=0.03)$. Sleep duration showed a close significant correlation with markers of insulin resistance. Poor sleep quality and inadequate sleep had a higher odds ratio of having insulin resistance [OR $=2.25$, (CI $0.96-5.24$ ), $\mathrm{p}=0.05$ ].

\section{CONCLUSIONS}

Short sleep duration and poor sleep quality were positively related with indicators of insulin resistance and poor glycaemic level.

\section{KEY WORDS}

Glycaemia, Insulin Resistance, Sleep Duration, Sleep Quality
Corresponding Author: Dr. Rachita Nanda, Department of Biochemistry, Room No-2121, AIIMS, Raipur, Tatibandh, Raipur, Chhattisgarh, India.

E-mail:dr.rachitananda@aiimsraipur.edu.in

DOI: $10.14260 / \mathrm{jemds} / 2020 / 775$

How to Cite This Article:

Venkatesan N, Nanda R, Patel $S$, et al. Impact of sleep patterns on glycaemic levels in healthy young adults. J Evolution Med Dent Sci 2020;9(47):3533-3537, DOI: 10.14260/jemds/2020/775

Submission 10-02-2020,

Peer Review 09-10-2020,

Acceptance 16-10-2020,

Published 23-11-2020.

Copyright (c) 2020 Nanditha Venkatesan et al. This is an open access article distributed under Creative Commons Attribution License [Attribution 4.0 International (CC BY 4.0)] 


\section{BACKGROUND}

It would not be wrong to say that diabetes is an epidemic that is spreading at an alarming rate worldwide and also in developing countries like India. ${ }^{1}$ It is therefore, equated as a silent epidemic. In India, there are approximately seventyfour million in India in the year 2017.1 The alarming aspect of diabetes however is the shift of age at onset in youth, notably among adolescents and young adults. In the recent (Indian Council of Medical Research) ICMR-India population based cross-sectional study, it was noted that at the age group of 25 - 34 years diabetes gets going both in rural and urban areas. ${ }^{2}$ Apart from genetic inheritance the other risk factors identified are the burgeoning obesity, change in food habits, physical inactivity, stress, alcohol and tobacco use. Recent research has started to identify sleep as a key process for maintenance of good metabolic health. One third of our lives is spent on sleeping, and these eight hours of night sleep regulates our metabolism. ${ }^{3}$ However, in the 21st century, because of a technology and gadget driven competitive professional environment, a sound sleep for eight hours is what many individuals are deprived of. Proper sleep hygiene is a variety of different practices and habits necessary to have adequate sleep both in quality and quantity that provides adequate physical and mental rest to the human body and full day time alertness. ${ }^{4}$ In the event of poor sleep hygiene, coupled with lack of physical activity and excess calorie consumption, the productive age group, i.e., the young individuals of our society are affected. Sleep debt, refers to increased demand for sleep that results from a lack of physiologically normal sleep. 5 Sleep debt, both acute and chronic have harmful effects on carbohydrate metabolism, as noted by a higher insulin response to oral glucose tolerance test. 6 Meta-analysis shows the evidence of a U-shaped association between sleep duration and incident diabetes mellitus. ${ }^{7,8}$ Hence, not only short but long duration of sleep are associated with incident diabetes. 9,10 The 2017 Standards of Care in Diabetes released by the American Diabetes Association (ADA), recommends that sleep pattern and duration must be assessed during medical evaluation of all diabetics as glycaemic control is dependent on sleep quality. ${ }^{11}$ Therefore, sleep hygiene is being recognized as a novel, modifiable risk factor for metabolic problems like insulin resistance and diabetes mellitus. ${ }^{12,13}$ Most studies have shown that diabetes is associated with poor sleep quality and sleep disorders. ${ }^{14,15,16}$ The prevalence of diabetes is increasing at an alarming proportion in young individuals, due to a complex interaction between genetic and environmental factors with an additional possibility due to sleep deprivation. It is critical that body bears this insult of poor sleep hygiene for a long period of time, in the adolescent and young adult period before presenting as diabetes. According to the National Sleep Foundation's sleep time duration recommendation, the number of hours of sleep for the age group $18-25$ years is $7-9$ hours. ${ }^{17}$ Certain professions are also associated with varying degrees of sleep deprivation. Still no emphasis is laid out on lifestyle modification in young adults to combat diabetes prophylactically, given the gravity of the spread of diabetes as an epidemic in India.

This study sought to evaluate the association of sleep quality and sleep duration with markers of insulin resistance for risk assessment of diabetes mellitus in apparently healthy young adults. This research is important because insulin resistance goes undetected and undiagnosed in apparently healthy young adults. Knowing the association is important, as it will help to plan preventive measures to control the development of insulin resistance and incident diabetes mellitus.

\section{METHODS}

This is an institute based cross-sectional study consisting of medical students who were enrolled by voluntary participation over a period of two months (July-August 2017). After approval by the Institutional Ethics Committees, a message had been circulated in the social media groups of the students to invite students to be a part of the study. Inclusion criteria were; students between 19 - 25 years of age of either gender and of any semester could enrol for the study. The exclusion criteria were; students diagnosed with sleep disorder, either a known case or a newly diagnosed case of diabetes mellitus or with other diseases like hypothyroidism, polycystic ovarian disease, liver or kidney disease, autoimmune disease and infection. Based on the above criteria one hundred fifteen students were enrolled as participants for the study. Prior instructions had been given so that students arrive in a fasting state on any of the weekdays, in the morning, with light clothing. After obtaining written consent, they were asked to fill up Pittsburgh Sleep Quality Index (PSQI), ${ }^{18}$ as well as another questionnaire with regard to information on their lifestyle (alcohol intake, habits regarding usage of mobile phones, physical activity), dietary habits and family history. PSQI, a questionnaire rated by selfevaluates sleep quality and sleep disturbances over the previous month. A global score is given according to the different components where a higher score reports towards worsening of sleep quality. The global score ranges from ' 0 ' to '21' where a score $>5$ suggests poor sleep quality. A global PSQI score $>5$ had sensitivity of $89.6 \%$ and specificity of 86.5 $\%$ for patients and normal middle-aged controls. ${ }^{19}$ Age, sex and anthropometric (height, weight, waist and hip measurement) information was also measured. Height was measured without shoes to the nearest $0.1 \mathrm{~cm}$ using a stadiometer. Students were asked to stand with the centre back on the stadiometer with four points of contact, i.e., heels, buttocks, back of the head and upper back. The top of the stadiometer rested firmly, on the top of the head of the participant. Weight, without shoes to the nearest $0.1 \mathrm{Kg}$ was recorded using a digital weighing scale. Height and weight were taken twice and the mean of the two measurements was used to calculate the body mass index (BMI). Waist and hip circumference were noted with the use of a metric tape to the nearest $0.5 \mathrm{~cm}$. Waist circumference was measured mid-way around the direct line that connects the lower costal margin and anterior-superior iliac spine at the end of normal expiration, with arms extended and aligned with the body. Hip circumference was measured around the widest portion of the buttock with the tape parallel to the floor.

Blood samples were also collected for glucose, lipids (total cholesterol, HDL cholesterol, LDL cholesterol and triglycerides) and insulin using the Beckman Coulter AU 680 analyser and Siemens Advia Centaur XP immunoassay 
analyser. Insulin resistance was determined using fasting insulin, homeostatic model assessment of insulin resistance (HOMA-IR): [fasting glucose $(\mathrm{mmol} / \mathrm{L}) \times$ fasting insulin $(\mathrm{mU}$ / mL)] / 225 and McAuley Index: exp [2.63 - 0.28 ln (Insulin $\mathrm{mIU} / \mathrm{L}$ ) $-0.31 \ln$ (triglycerides (mmol / L)].

Within a period of two months a total of 115 students were enrolled for the study. Out of the 115 students, analyses were done for ninety participants as the rest had incomplete forms. During data analysis the study population was grouped based on sleep duration at night; Adequate Sleep Duration (ASDN) with $>7$ hours and Inadequate Sleep Duration (IASDN) with $<7$ hours of sleep. A fasting insulin level $\geq 12 \mathrm{mIU} / \mathrm{L}$ as the cut -off to define insulin resistance in subjects with normal glucose and lipid profile, ${ }^{20}$ was also used for categorising the participants and calculating the risk of developing hyperinsulinaemia after adjusting for BMI. An increase in BMI is an indicator of increase in adipokines from these white adipose tissues, which helps in development of hyperinsulinaemia and later insulin resistance.

\section{Statistical Methods}

Data were reported as mean \pm Standard Deviation (SD). To compare continuous and categorical variables independent $\mathrm{t}$ test and chi square test were used. Correlation coefficients were calculated by Spearman correlation. The Odds Ratio (OR) with $95 \%$ Confidence Interval (CI) was estimated using logistic regression for risk category stratified by sleep quality and sleep duration. Statistical analysis was done with Graph Pad Prism 5.0 statistical software and $\mathrm{p}<0.05$ has been considered as significant.

\section{RESULTS}

A total of ninety students, forty-six males and forty-four females with a mean age of around 20 years was enrolled in the study. Twenty-one students (23.3\%) regularly played some outdoor sports at least for 3 hours a week, 13 of the 90 $(14.4 \%)$ had either one of the parent suffering from diabetes mellitus and only $11.1 \%$ had alcohol in the past one month. When comparing the general characteristics, laboratory investigations and calculated markers of insulin resistance in both genders, only the waist circumference in males, was significantly more than females as shown in Table 1. A similar number of participants were in the two groups of adequate and inadequate sleep duration. Participants with inadequate sleep duration had significantly higher BMI $(p=0.02)$, fasting insulin $(p=0.01)$ and lower McAuley index $(p=0.03)$ when compared with those with adequate sleep duration as summarized in Table 2 .

A positive correlation $(p=0.01)$ of insulin with BMI and significant negative correlation of McAuley index with insulin ( $\mathrm{p}=0.03)$, HOMA-IR ( $\mathrm{p}=0.05)$, BMI $(\mathrm{p}=0.04)$ and sleep duration $(p=0.04)$ is depicted in Table 3. The association between insulin and sleep quality and sleep duration was identified in both the groups by logistic regression, after adjustment for BMI to calculate the odds ratio. Those participants who had poor quality sleep had a 2.25 times odds (CI $0.96-5.24$ ) of having insulin resistance $\left(\mathrm{I}_{0}>12 \mathrm{mIU}\right.$ / L), which was statistically significant ( $p=0.05)$. Similarly, participants who slept for $<7$ hours also had a statistically significant $(p=0.02)$ odds ratio of 2.7 (CI $1.16-6.55)$ as shown in Table 4.

\begin{tabular}{|cccc|}
\hline \multicolumn{1}{|c|}{ Parameters } & $\begin{array}{c}\text { Males } \\
(\mathbf{n}=\mathbf{4 6})\end{array}$ & $\begin{array}{c}\text { Females } \\
(\mathbf{n}=\mathbf{4 4})\end{array}$ & $\mathbf{P}$ \\
\hline Age (yr.) & $20.6 \pm 1.1$ & $20.6 \pm 1.0$ & 1.0 \\
\hline Systolic blood pressure (mmHg) & $128.9 \pm 14.2$ & $124.5 \pm 10.5$ & 0.099 \\
\hline Diastolic blood pressure mmHg) & $77.8 \pm 6.9$ & $78.4 \pm 9.5$ & 0.731 \\
\hline BMI (Kg / m²) & $24.7 \pm 3.2$ & $24.2 \pm 4.0$ & 0.513 \\
\hline Waist Circumference (cm) & $77.6 \pm 7.6$ & $74.6 \pm 7.1$ & 0.056 \\
\hline Hip Circumference (cm) & $96.9 \pm 8.3$ & $99.1 \pm 9.0$ & 0.2310 \\
\hline W / H ratio & $0.80 \pm 0.06$ & $0.78 \pm 0.05$ & 0.090 \\
\hline Sleep duration (h) & $6.8 \pm 0.8$ & $6.7 \pm 1.4$ & 0.676 \\
\hline Global PSQI score & $6.6 \pm 1.1$ & $6.4 \pm 1.0$ & 0.369 \\
\hline FPG (mg / dL) & $74.9 \pm 6.9$ & $72.8 \pm 5.9$ & 0.125 \\
\hline Fasting Insulin (mIU / L) & $12.77 \pm 5.15$ & $12.3 \pm 3.8$ & 0.624 \\
\hline Total cholesterol (mg / dL) & $174.3 \pm 36.4$ & $171.4 \pm 28.9$ & 0.677 \\
\hline Triglycerides (mg / dL) & $131.7 \pm 29.8$ & $120.9 \pm 34.1$ & 0.112 \\
\hline HDL cholesterol (mg / dL) & $59.37 \pm 12.4$ & $63.29 \pm 11.9$ & 0.129 \\
\hline LDL cholesterol (mg / dL) & $88.9 \pm 8.9$ & $86.5 \pm 7.1$ & 0.162 \\
\hline HOMA-IR & $2.7 \pm 1.7$ & $2.8 \pm 1.9$ & 0.792 \\
\hline McAuley index & $7.1 \pm 1.4$ & $6.8 \pm 1.5$ & 0.329 \\
\hline Table 1. General Characteristics, Laboratory Investigations and \\
Markers of Insulin Resistance in the Study Population \\
\hline
\end{tabular}

\begin{tabular}{|cccc|}
\hline & $\begin{array}{c}\text { ASDN (n= 49) } \\
\text { (M:F::26:23) }\end{array}$ & $\begin{array}{c}\text { IASDN (n = 41) } \\
\text { (M:F::20:21) }\end{array}$ & P \\
\hline Age (yr.) & $20.44 \pm 0.99$ & $20.86 \pm 1.12$ & 0.062 \\
Systolic blood pressure (mmHg) & $125.2 \pm 11.7$ & $127.5 \pm 8.9$ & 0.304 \\
Diastolic blood pressure (mmHg) & $77.8 \pm 6.9$ & $78.4 \pm 9.5$ & 0.687 \\
\hline BMI (Kg / m²) & $23.8 \pm 2.5$ & $25.2 \pm 3.4$ & 0.027 \\
\hline Waist Circumference (cm) & $74.1 \pm 6.2$ & $75.4 \pm 8.9$ & 0.418 \\
\hline Hip Circumference (cm) & $96.8 \pm 6.5$ & $97.4 \pm 8.9$ & 0.713 \\
\hline Global PSQI score & $6.4 \pm 1.1$ & $6.7 \pm 1.0$ & 0.182 \\
FPG (mg / dL) & $74.4 \pm 5.9$ & $73.3 \pm 7.2$ & 0.427 \\
\hline Fasting Insulin (mIU / L) & $13.7 \pm 4.1$ & $15.9 \pm 4.3$ & 0.015 \\
Total cholesterol (mg / dL) & $176.8 \pm 26.7$ & $179.3 \pm 23.5$ & 0.641 \\
\hline Triglycerides (mg / dL) & $121.6 \pm 22.8$ & $132.5 \pm 31.7$ & 0.061 \\
\hline HDL cholesterol (mg / dL) & $65.4 \pm 11.8$ & $63.2 \pm 9.5$ & 0.339 \\
\hline LDL cholesterol (mg / dL) & $90.3 \pm 11.4$ & $86.9 \pm 10.4$ & 0.146 \\
\hline HOMA - IR & $2.8 \pm 1.7$ & $3.0 \pm 1.4$ & 0.549 \\
\hline McAuley Index & $7.2 \pm 1.2$ & $6.6 \pm 1.5$ & 0.037 \\
\hline Table 2. General Characteristics, Laboratory Investigations and \\
Markers of Insulin Resistance in ASDN and IASDN Groups \\
\hline
\end{tabular}

\begin{tabular}{|c|c|c|c|c|c|c|}
\hline & BMI & Glucose & Insulin & HOMA-IR & $\begin{array}{l}\text { McAuley } \\
\text { Index }\end{array}$ & $\begin{array}{c}\text { Sleep } \\
\text { Duration }\end{array}$ \\
\hline BMI & \multicolumn{6}{|c|}{1} \\
\hline Glucose & $0.06(0.29)$ & 1 & & & & \\
\hline Insulin & $0.12(0.01)$ & $0.04(0.38)$ & 1 & & & \\
\hline HOMA-IR & $0.03(0.40)$ & $0.03(0.46)$ & 0.08 & 1 & & \\
\hline $\begin{array}{l}\text { McAuley } \\
\text { Index }\end{array}$ & $-0.26(0.04)$ & $0.07(0.14)$ & $-0.10(0.03)$ & $-0.68(0.05)$ & 1 & \\
\hline $\begin{array}{c}\text { Sleep } \\
\text { duration }\end{array}$ & $0.03(0.45)$ & $0.05(0.22)$ & $-0.02(0.51)$ & $-0.04(0.41)$ & $\begin{array}{l}-0.35 \\
(0.04) \\
\end{array}$ & 1 \\
\hline \multicolumn{7}{|c|}{$\begin{array}{l}\text { Table 3. Correlation Matrix of Metabolic Parameters } \\
\text { and Sleep Duration in the Study Population }\end{array}$} \\
\hline
\end{tabular}

\begin{tabular}{|c|c|c|c|c|}
\hline Variables & $\begin{array}{c}I_{0}<12 \mathrm{mU} / \mathrm{L} \\
(\mathrm{n}=45)\end{array}$ & $\begin{array}{c}I_{0} \geq 12 \mathrm{mU} / \mathrm{L} \\
(\mathrm{n}=45)\end{array}$ & OR (95 \% CI) & P Value \\
\hline \multicolumn{5}{|c|}{ Sleep Quality } \\
\hline Good & 26 & 17 & 1 & \\
\hline Poor & 19 & 28 & $2.25(0.96-5.24)$ & 0.05 \\
\hline \multicolumn{5}{|c|}{ Sleep Duration } \\
\hline$\geq 7$ hours & 31 & 20 & 1 & \\
\hline$<7$ hours & 14 & 25 & $2.7(1.16-6.55)$ & 0.02 \\
\hline \multicolumn{5}{|c|}{$\begin{array}{l}\text { Table 4. Logistic Regression Model of Insulin } \\
\text { with Sleep Quality and Quantity }\end{array}$} \\
\hline
\end{tabular}




\section{DISCUSSION}

The results of this study reveal that sleep duration of less than seven hours and poor quality sleep with global PSQI score more than 5 is a risk factor for insulin resistance in apparently healthy young adults. Similar findings were reported by Mander et $\mathrm{al}^{21}$ where decreased sleep duration resulted in significant higher levels of insulin secretion when glucose levels are normal. The insulin sensitivity of these short sleepers was also lower than normal. Other studies have also concluded that short sleep durations, a single night of partial sleep deprivation and sleep restriction even for one week, in healthy individuals induces insulin resistance or reduces insulin sensitivity with also an increase in insulin level.22,23,24,25 There are very few studies providing insight into the alteration in glucose metabolism in young adults.

The recommended sleep time for young adults between 18 - 25 years is 7 - 9 hours, with a low risk of type 2 diabetes when the duration of sleep is $7-8$ hours per day. ${ }^{26}$ Our study reveals that participants who had inadequate sleep, BMI was in the range of overweight category, which was significantly high from participants who had adequate sleep of $>/=7$ hours. Shaikh et al., in a study on Indian adolescents had shown that sleep deprivation predisposes to obesity. ${ }^{27}$ Other studies have also depicted that patients with poor sleep had higher BMI. ${ }^{28}$ In a study of the Fukuoka Diabetes Registry, as the sleep duration reduced it was associated with an increased BMI and proportion of obese subjects. ${ }^{29}$ In the same study subjects with shorter duration of sleep had a higher propensity for obesity than those with a sleep duration of 6.5 - 7.4 hours. Sleep deprived subjects had high appetite for carbohydrate rich foods, they also overeat and eat fast which contributes to their obesity. Sleep restriction causes elevation of orexigenic factor ghrelin and decrease in anorexigenic hormone leptin thus regulating eating behaviour of an individual and compromising insulin sensitivity. ${ }^{6,30,31}$

A cut-off point of fasting insulin level of $>12 \mathrm{mIU} / \mathrm{L}$, HOMA-IR of $>2.6$ and McAuley index $<5.8$ was used to define insulin resistance. 20,32 Amongst the indirect indices of insulin resistance, fasting insulin was significantly higher in subjects with inadequate sleep at night, while HOMA-IR was nonsignificantly high. In a study of individuals with normal basal glucose, it was observed that short sleepers had a significantly higher levels of C-peptide, which is a marker of insulin secretion than normal sleepers. A study by Matthews et. al., in adolescents noted that reduce sleep duration was associated with raise HOMA-IR, linking it to diabetes in adulthood. ${ }^{33}$ However, an ancillary study to the Coronary Artery Risk Development In young adults (CARDIA) study, found no relation between sleep measures, and insulin or HOMA-IR in subjects without diabetes. However, in diabetic subjects there was some association of sleep fragmentation with insulin and HOMA-IR. ${ }^{34}$

The other index of insulin resistance, the McAuley index is used for predicting insulin resistance in normoglycaemic individuals. Although, the value declined significantly in inadequate sleepers in comparison to adequate sleepers it is more than the cut-off point of 5.8 which has been acknowledged by authors. ${ }^{20,32}$

A positive and significant correlation of insulin with BMI suggests linking of insulin resistance with metabolic syndrome. Similarly, significant negative correlation of McAuley Index with BMI supports the above suggestion. We found that the McAuley index was a more sensitive measure of the impact of sleep duration on insulin resistance. The quality of sleep also affects insulin resistance as described by Koren et al. ${ }^{35}$ Subjects with poor quality sleep and with less duration of sleep had a higher risk of insulin resistance, it is imperative that the study population is at risk of developing diabetes mellitus over a prolonged period of time. A metaanalysis of prospective studies has shown that a short and long duration of sleep is associated with an elevated risk for type 2 diabetes mellitus. The study also concluded that a time of seven hours sleep is optimum for an adult and decrease of one hour in sleep is associated with a $9 \%$ risk of type 2 diabetes mellitus.

Young adults with a mean age of around 20 years having the above correlation indicates a link between sleep deprivation and glucose metabolism. These students have spent two years in the medical school and prior to it they have spent two to three years in completing their senior secondary course and preparation for the medical entrance. Most young adults follow this life style while preparing for entrance and after that when they come to technical institutes. Diabetes mellitus which is said to affect the population at an age around 40 years has a foundation which is almost two decades prior to the onset of disease. The above findings suggest that it is imperative to improve the sleep quality and quantity and thus the sleep hygiene and improving the physical activity to keep the disease away at an arm's length if not prevent it from ever occurring. As they say that prevention is better than cure, an ideal sleep schedule should be the intervention strategy in not only preventing but also management of type 2 diabetes mellitus.

\section{CONCLUSIONS}

The study had some limitations. The main limitation was the number of participants. This is a pilot study that aimed at assessing the effects of sleep disturbances on parameters of insulin resistance; however, since this is a cross-sectional study, and it limits elucidating the causality of insulin resistance. Participants of this study involved a discrete group, and it needs additional research to evaluate generalizability of results to similar population. Prospective study in young adults can help establish causality of poor sleep hygiene with abnormal glucose metabolism. In conclusion, the study demonstrated that inadequate sleep and poor quality of sleep was closely associated with subtle but significant change in insulin resistance.

Data sharing statement provided by the authors is available with the full text of this article at jemds.com.

Financial or other competing interests: None.

Disclosure forms provided by the authors are available with the full text of this article at jemds.com.

\section{REFERENCES}

[1] IDF Diabetes Atlas-8e-regional-fact-sheet-18-99-SEA.pdf. [2] Mohan V, Amutha A, Ranjani H, et al. Clinical approach 
to diabetes in the young in India. The Association of Physicians of India 2013:156-61.

[3] Stamatakis KA, Punjabi NM. Effects of sleep fragmentation on glucose metabolism in normal subjects. Chest 2010;137(1):95-101.

[4] Sleep https://www.sleepfoundation.org/articles/sleephygiene

[5] Banks S, Dorian J, Basner M, et al. Sleep deprivation. In: Kryger M, Roth T, Dement WC, ed. Principles and practice of sleep medicine. $6^{\text {th }}$ edn. Philadelphia: Elseiver Inc 2017:49-55.

[6] van Helder T, Symons JD, Radmoski MW. Effect of sleep deprivation and exercise glucose tolerance. Aviat Space Environ Med 1993;64(6):487-92.

[7] Cappuccio FP, D'Elia L, Strazzullo P, et al. Quantity and quality of sleep and incidence of type 2 diabetes: a systematic review and meta-analysis. Diabetes Care 2010;33(2):414-20.

[8] Shan Z, Ma H, Xie M et al. Sleep duration and risk of type 2 diabetes: a meta-analysis of prospective studies. Diabetes Care 2015;38(3):529-37.

[9] Kita T, Yoshioka E, Satoh H, et al. Short sleep duration and poor sleep quality increase the risk of diabetes in Japanese workers with no family history of diabetes. Diabetes Care 2012;35(2):313-8.

[10] Beihl DA, Liese AD, Haffner SM. Sleep duration as a risk factor for incident type 2 diabetes in a multiethnic cohort. Ann Epidemiol 2009;19(5):351-7.

[11] American Diabetic Association. 3. Comprehensive medical evaluation and assessment of comorbidities. Diabetes Care 2017;40(Suppl 1):S25-32.

[12] Lou P, Zhang P, Zhang L, et al. Effects of sleep duration and sleep quality on prevalence of type 2 diabetes mellitus: a 5-year follow-up study in China. Diabetes Res Clin Pract 2105;109(1):178-84

[13] Spiegel K, Knutson K, Leproult R, et al. Sleep loss: a novel risk factor for insulin resistance and type 2 diabetes. J Appl Physiol 2005;99(5):2008-19.

[14] Luyster FS, Dunbar-Jacob J. Sleep quality and quality of life in adults with type 2 diabetes. Diabetes Educ 2011;37(3):347-55.

[15] Chasens ER, Luyster FS. Effect of sleep disturbances on quality of life, diabetes self-care behaviour, and patientreported outcomes. Diabetes Spectr 2016;29(1):20-3.

[16] Iyer SR. Sleep and type 2 diabetes mellitus-clinical implications. JAPI 2012;60:42-7.

[17] Hirshkowitz M, Whiton K, Albert SM, et al. National Sleep Foundation's sleep time duration recommendations: methodology and result summary. Sleep Health 2015;1(1):40-3.

[18] Buysse DJ, Reynolds CF, Monk TH, et al. The pittsburgh sleep quality index: a new instrument for psychiatric practice and research. Psychiatric Res 1989;28(2):193213.

[19] Panda S, Taly AB, Sinha S, et al. Sleep-related disorders among a healthy population in South India. Neurol India 2012;60(1):68-74

[20] Ascaso JF, Pardo S, Real JT, et al. Diagnosing insulin resistance by simple quantitative methods in subjects with normal glucose metabolism. Diabetes Care 2003;26(12):3320-5.

[21] Mander BA, Colecchia E, Spiegel K, et al. Short sleep: a risk factor for insulin resistance and obesity. Diabetes 2001;50(Suppl 2):A45.

[22] Wong PM, Manuck SB, DiNardo MM, et al. Shorter sleep duration is associated with decreased insulin sensitivity in healthy white men. Sleep 2015;38(2):223-31.

[23] Buxton OM, Pavlova M, Reid EM, et al. Sleep restriction for 1 week reduces insulin sensitivity in healthy men. Diabetes 2010;59(9):2126-33.

[24] Donga E, van Dijk M, van Dijk JG, et al. A single night or partial sleep deprivation induces insulin resistance in multiple metabolic pathways in healthy subjects. J Clin Endocrinol Metab 2010;95(6):2963-8.

[25] Schmid SM, Hallschmid M, Jauch-Chara K, et al. Disturbed glucoregulatory response to food intake after moderate sleep restriction. Sleep 2011;34(3):371-7.

[26] Ascaso JF, Pardo S, Real JT, et al. Diagnosing insulin resistance by simple quantitative methods in subjects with normal glucose metabolism. Diabetes Care 2003;26(12):3320-5.

[27] Shaikh WA, Patel M, Singh SK. Sleep deprivation predisposes Gujarati Indian adolescents to obesity. IJCM 2009;34(3):192-4.

[28] Aribas A, Kayrak M, Tekinalp M, et al. The relationship between serum asymmetric dimethylarginine levels and subjective sleep quality in normotensive patients with type 2 diabetes mellitus. Korean J Intern Med 2015;30(3):316-24.

[29] Okhuma T, Fujii $H$, Iwase $M$, et al. Impact of sleep duration on obesity and the glycaemic level in patients with type 2 diabetes: the Fukuoka Diabetes Registry. Diabetes Care 2013:36(3):611-7.

[30] Knutson KL. Impact of sleep and sleep loss on glucose homeostasis and appetite regulation. Sleep Med Clin 2007;2(2):187-97.

[31] Spiegel K, Tasali E, Penev P, et al. Brief communication: sleep curtailment in healthy young men is associated with decreased leptin levels, elevated ghrelin and increased hunger and appetite. Ann Intern Med 2004;141(11):846-50.

[32] Hettihewa LM, Weerarathna TP. Comparison of McAuley/fasting insulin indices with ATP III clinical criteria for the diagnosis of insulin resistance in type 2 diabetes mellitus. J Pharmacol Phramacother 2011;2(3):165-9.

[33] Matthews KA, Dahl RE, Owens JF, et al. Sleep duration and insulin resistance in healthy black and white adolescents. Sleep 2012;35(10):1353-8.

[34] Knutson KL, van Cauter E, Zee P, et al. Cross-sectional associations between measures of sleep and markers of glucose metabolism among subjects with and without diabetes. the Coronary Artery Risk Development in Young Adults (CARDIA) Sleep Study. Diabetes Care 2011;34(5):1171-6.

[35] Koren D, Gozal D, Philby MF, et al. Impact of obstructive sleep apnoea on insulin resistance in nonobese and obese children. Eur Respir J 2016;47(4):1152-61. 